QSLa $\begin{aligned} & \text { Binyam Sisay Mendisu \& Janne Bondi Johannessen (eds.) Multilingual Ethiopia: Linguistic Chal- } \\ & \text { lenges and Capacity Building Efforts, Oslo Studies in Language 8(1), 2016. 339-357. (ISSN 1890- }\end{aligned}$
http://www. journals.uio.no/osla

\title{
SOCIO-POLITICAL DISCOURSE AND COMMUNICATION IN SIDAAMA FOLK MEDIA
}

\author{
NIGUSSIE MESHESHA MITIKE \& KJELL MAGNE YRI
}

\section{ABSTRACT}

The aim of this study was to highlight aspects of the socio-political discourse and communication in Sidaama through the analysis of three selected Sidaama folk media. Folk media include songs, proverbs, folktales, praises, curses, greetings and so on, but this contribution is limited to examples of hano "dance of married adults", faaro "song (with a wide variety of topics)", and hayye "lullaby", a representative but by no means complete selection. Dances are accompanied by poetic discourse that may be used for political and social ends. The selected material was subject to linguistic and contextual analysis, demonstrating the treatment of a variety of political and social topics in the folk media.

\section{[1] INTRODUCTION ${ }^{1}$}

Many studies of political communication employ a rhetorical and discourse analysis approach (Nimmo and Sanders 1981). Discourse analysis is useful in the study of political communication because it contributes towards understanding deeper levels of meaning, through examination of how language is used to represent people of a certain group, class or race. The existing communication systems can shape and be shaped by the political structure, as differences are usually under or overplayed for competing political and ideological reasons. Such forms of political communication are usually made for the production or reproduction of social reality through language use (Mayr 2008).

In relation to this, the study has focused on discourse and communication analysis of Sidaama folk media in portraying socio-political realities. Folk media can be best referred to as indigenous equivalents of exogenous mass media. They include festivals, plays, puppet shows, dance, songs, storytelling and poetry (Valbuena 1986). Of the various indigenous channels, the folk media highly shape the political and social activities. This is because, according to Kumar (2006:95): “The traditional media are close to the hearts and minds of the peo-

[1] Professor Yri's contribution is mainly in relation to the Sidaama examples and their translation and analysis. 
ple, so their appeal is at personal, intimate level" and also "satisfy our innate need for self-expression, for moral instruction combined with entertainment".

Hence, studying the socio-political discourse and communication system would help to learn how language functions, and how meaning is created and understood in Sidaama folk media. From this vantage point, the present study has attempted to analyse how the Sidaama folk media are used to portray different socio-political realities by focusing on linguistic analysis.

\section{[2] BACKGROUND AND PROBLEM STATEMENT}

\section{[2.1] Background}

The language of the Sidaama people, often referred as Sidaamu afoo (as in Yri 2011), belongs to the Cushitic family and is numerically one of the top six languages in Ethiopia with its 2.9 million native speakers, according to the 2007 census published by The Central Statistical Authority of Ethiopia, (2010:200). A recent estimate states that there are more than four million speakers of the language (http://joshuaproject.net/people_groups/14630/ET).

The Sidaama have a number of clans, named after their forefathers who descended from their common great ancestors called Bushe and Maldea. Some elderly volunteer informants for the study said the major clans in Sidaama are seven, but others suggest that there are 12 (consider also Murdoch (1959) and Betana (1991)). The Sidaama people were part of the former Sidamo Teqlay Gizat 'province' during Haile Sellassie's regime and Sidamo's Kifle Hager "region" during the Marxist regime.

According to Hudson (2006) the Sidaama used to administer themselves and have kept their culture and tradition intact for many years. However, there were some historical and social factors that have influenced the culture and tradition. First, the Sidaama self-administration was affected by Menelik's expansion to the South when Sidaama came under Emperor Menelik II who ruled between 1889 and 1909 (consider too Henze 2001 and Bahru \& Pausewang 2002). Second, the neo evangelization process resulted in many changes, such as in the dressing, eating and many ritualistic activities of the people. In the third place, there was the feudal regime of Haile Sellasie, which required the homogenization of Ethiopian cultures, and the Marxist-led ideology of the Derg regime in Ethiopia, which looked at local cultures as a retarding force to development. These views have left their own negative impact on the Sidaama culture, as with all the others. Fourth, the better access people got to modern education and the expansion of roads and other infrastructure, including access to media, etc. have all paved the way for new ways of living among the people. Fifth, the subsequent empowerment of women and the younger generation in 
recent years have also brought changes in the people's life style.

Even though some of the changes presented above brought various changes to the cultural heritage of the Sidaama, some of it is widely practiced through folk media. This is commonly observed among adults when they mainly practice affini or affino "the customary adjudication system", fichche "new year celebration", luwa "the age and political system", qeet'ala "joyous feast", barch'uma "circumcision", as well as in numerous other social institutions.

\section{[2.2] Problem Statement and Objectives}

The Sidaama language and culture can be considered as one of the relatively well-studied ones among the Cushitic peoples of Ethiopia. Some of the major studies which focus on the socio-political and cultural aspects of Sidaama include Markos (2014), Markos et al (2011), Hudson (2006), Betana (1991) and Hamar (1970). In addition to this there are various investigations made by linguists on the language Sidaamu afoo. Major studies that deserve to be mentioned here include Tafesse (2015), Girum (2013), Anbessa $(2007,1987)$ and Yri $(2011,2004)$. Though different studies are available on the socio-cultural and linguistic aspects of the Sidaama, there is not much research examining Sidaama folk media in the light of discourse. Some of the existing related works include Nigussie $(2005,2015)$ and Mesay $(2016)$. However, they do not specifically deal with the socio-political discourse system of Sidaama folk media. By focusing on the examination of selected folk media, the present study wishes to contribute to fill the research gap.

The main objective of the study is, therefore, to identify and analyse sociopolitical discourse and communication aspects of Sidaama, through the linguistic analysis of selected Sidaama folk media, namely hano, faaro and hayye.

\section{[3] CONCEPTUAL FRAMEWORK}

This study employs discourse analysis and speech act theory as its conceptual framework. Discourse analysis is used in order to identify the deeper level of meaning made by a society on socio-political matters. In relation to this, Morand (2000: 37) notes the importance of discourse analysis in political communication by writing that 'power and politics are frequently exercised through the discourse made in institutions'. In a similar vein, the Sidaama use their own traditional practices and institutions to exercise power and politics among their members. The way people use the folk media as a discourse channel in different social institutions legitimizes power and politics among the people. This is observed through the analysis of language that demonstrates how power is enacted and communicated in superior or subordinate relations. 
Consequently, discourse analysis indicates the dominant patterns of representation of people in politics, media and language use, Shohat \& Stam (1994). According to Van Dijk (1993), discourse analysis may reveal how social power is misused, dominance is created, and inequality is reproduced and resisted using communication media in the social and political contexts. Van Dijk actually refers to this as critical discourse analysis (CDA). Discourse analysis reveals the existing social and political relations of the oppressed and the oppressor, or the subordinate and the dominant positions being "discursively framed, constructed, reproduced or perpetuated", Morand (2000).

Beside the investigation of the discourse forms, John Austin's speech act principles are employed to analyse the selected folk media. Austin (1962: 3) delivering the William James Lectures at Harvard University in 1955 said "many utterances which look like statements are either not intended at all, or only intended in part" for sharing or recording some sort of explicit information about the facts. This may probably indicate that any form of representation through language or words can be intentional or partly intentional, but it is part of doing actions through words, as Austin puts it in his book 'How to do Things with Words'. According to him "ethical propositions", for instance, could be solely or partly intended 'to evince emotion or to prescribe conduct or to influence it in special ways'.

Austin claimed that utterances meet two salient conditions: first, that "utterances do not 'describe' or 'report' or 'constate' (not all true or false statements are descriptions) anything at all, are not 'true or false'; and [second] the uttering of the sentence is, or is a part of, the doing of an action". According to Austin the doing of actions may involve three acts: locutionary, perlocutionary and illocutionary acts. Based on Austin, Oishi (2006) discusses the three acts. Locutionary acts include phonetic acts, phatic acts, and rhetic acts. 'Phonetic acts are acts of pronouncing sounds, phatic acts are acts of uttering words or sentences in accordance with the phonological and syntactic rules', and rhetic acts are performed by 'uttering a sentence with sense and more or less definite reference'. The perlocutionary acts are about the effect of uttering a sentence. The illocutionary acts are performed by uttering a sentence by the speaker to perform an act having a certain force. These acts are speech acts which are performed in communication situations, conversations, or making discourses, Moeschler (u.d:2).

In relation to this, Morand (2000) also talks about how discourse is made within the various texts that help to perform acts. Discourse analysis usually helps to identify an ideology, a political structure, and a communication system, with the acts performed through the texts. Discourse in a text can be un- 
derstood by studying the use of language in a communication context. This is because language and discourse are inextricably linked and any sort of discourse produced and reproduced in media, literature, science and technology is undertaken through language in order to perform some sort of acts, Syal and Jindal (2002: 10).

\section{[4] METHODS OF THE STUDY}

The study was carried out by employing explorative and qualitative research design so as to unveil the linguistic, cultural and communication realities that are little studied about Sidaama. The study is mainly a qualitative one and it makes use of key informant interviews, Focus Group Discussion (FGD), and observation. The interviews were carried out with elderly people who have a lot of knowledge about the Sidaama culture and tradition and are known for their familiarity with the Sidaama oral history, cultural rite and folk media. The FGD was conducted for live coverage of the songs and verbal and nonverbal communication of the people. Observation was used to study how the people perform their songs, and to examine the nonverbal communication styles of the people.

As it was a qualitative research design, the researcher first selected informants by obtaining information about the extent to which the candidates could provide useful information. Someone who was said to be knowledgeable was first found and asked, and he further led to the second person who could contribute further and so on through the snowball sampling method. The informants were taken from three clans, viz. Garbicho in the Aleta Wondo area, Chuko from the Aleta Chuko woreda, and Habela from the Shabedino woreda among the twelve clans presumably representing the highlander, the semi highlander and the township close to the lowland of Hawassa, respectively. FGD was also conducted in each place for the purpose of recording the discussions and the cultural songs, as well as some ritualistic activities.

\section{[5] ANALYSIS AND DISCUSSION}

The folk media included in this study are hano, faaro and hayye. Hano is a song/dance performed by married adults during holiday and festivities, including at the time of fichche and when they are gathered for other social purposes. The faaro is also performed by males and females together with an alluring dance at market places, also during New Year "fichche" celebrations. The hayye "lullaby" is usually practiced by mothers, e.g. when they carry their babies on their back or grind crops or when they put them to sleep at home. Young girls usually also learn this during their socialization in childhood from both their 
mothers and their locality. Praise and love songs are expressed with hano and faaro as folk media for socio-political criticisms, whereas hayye may be used for the same purposes, as well as for expressing world views.

In what follows, an example of each of the three selected folk media will be analysed linguistically in their discourse context, and various conclusions drawn from them will then be presented. The examples are represented as poems in orthographic notation, with idiomatic English translation. Wherever a line is extracted for linguistic analysis, morpheme analysis and glossing will be included.

\section{[5.1] Hano}

One of the functions of this Sidaama traditional poetry is to oppose unjust political practices performed by the perpetuators. It was used e.g. to express protests about the feudal administration and political system. Though many years have gone since feudal administration ended, still the people sing such songs to remember their historical oppression. When performing them today, they may allude to the past feudal and Marxist systems to ventilate present political and social grievances. The 'hano' songs do help the people to ventilate their grievances and the discourse here mainly refers to past political structure, but additionally alludes to the present.

The selected hano

lena lemboolena

introductory formula (lemboo alludes to "lemboola" pigeon)

ani ha'ro dayammara

let me go to come back (repeated twice)

lishshi assine kande

let us step on them hard

kuriuu diinnankera

on these our enemies

bushsha same maraa

they struggle for the soil and go

bushsha malkanyootaho

death over the oppressors

loosi'roommoha horre

he plundered what I had worked for

umisira gore

he slaughtered them (my animals) for himself

ani uurre la"anna 
while I stood looking at

isiniite itiha

the one who ate them for himself

sidaamu jajjabba'ya

my Sidaama elders (heroes)

mulla massine shinoonnita

that they were killed without any reason

habbooti hegerera "

do not forget it ever

The song is performed by mimicking the dance of the the bird wolliimma "golden feathered bird", here referred to as lemboola "pigeon". The dance imitates the movements of the bird's neck while dancing. There is open criticism of the feudal lords to whom the people had to pay tribute. Before the times of newspapers and twitter accounts this was an efficient channel through which to vent criticism of the oppression of the feudal lords.

Even though the introduction is that of a love song with reference to the grace of a dove, the song is full of harsh lexical items like diinna and malkagna with political implications. The second line in the song is sung twice and its verb has the subject suffix in the feminine form, indicating that the performer in the recorded sample is a woman. Her poetic message can best be interpreted in the context of a love song: "let me go/ I must go, but my intention is to come back." Hence, the introductory lines seem to be in harsh contrast to the remainder of the hano, that is to denounce oppression.

Obviously, the lines "let us step hard on our enemies", "they struggle for the soil and go", and "death over the oppressors" refer to the attitude towards oppression in Sidaama. The Sidaama were formerly marginalized from the political and economic participation. They were suffering victims of the political and economic system. Thus, they opposed the government of the time through words or the expressions they employed in their songs. The word bushsha, that has a concrete meaning "soil, land" is also used very negatively in the curse "soil (death!) to the oppressors" in the very next stanza.

The following lines of the hano give further adverse comments on the feudal practice: "he plundered what I had worked for; he slaughtered them (my animals) while I stood looking at the one who ate them for himself." The harsh words shorra "plunder" and gorra "slaughter" refer to the fact that the peasants had to bring sheep and goats to the land owners as tribute. The landlord used to usurp the fruits of the peasants' labour while the peasants were left destitute in their serfdom. It is described down to the disgraceful detail that the oppressor slaughtered and ate the animal while the poor man was watching. 
The background of such use of the language is e.g. the fact that the past feudal government might claim more than $3 / 4$ of the production of the peasants as land tax. The only way to protest against such governance was to denounce the custom in songs.

The actual function of this genre might be both to denounce the bad governance of the past and to criticize the present authorities, in whatever respect deemed necessary. Thus, the hano is used as a medium to communicate the message.

\section{[5.2] Hayye}

Usually the hayye "lullaby" is sung by mothers to soothe babies when they want them to sleep or when they are asleep. However, as in the case of hano, the topic may quickly shift to other, more social and political domains, for example opposing the acts of their husbands, the bad demeanour of the members of their societies, the political system, or passing along some other messages.

In general the Sidaama use their folk media to communicate to the young their political and social worries, dissatisfaction, or opposition. And the most commonly used genre in Sidaama folk media used for this purpose is the hayye. For example, in the selected hayye the women praise their queen Furra and curse the bad demeanour of her political opponents.

The selected hayye

ooso hayye hayye

children lullaby lullaby

Furra meentu biilo

Furra the queen of women

furra shihu shiimo

let the one who killed Furra become small

furra shiihu shiilo

let the one who killed Furra vanish

furra meentu biilo

Furra the queen of women

yanganynya ama furra

Hanganynya's mother Furra

furra shihu shiimo

let the one who killed Furra become small

furra noomme barra

during the time Furra was alive

laballu meentoho qishe 
husbands used to cook for wives

ka'e ka'e reyito ise

let her raise from the dead (literally: may she die again having risen, having risen)

Women chant this song with the aim of sending the child to sleep. It is, thus, a perlocutionary act. However, this text is also performed with an illocutionary force that consists in the opposing of the ill-treatment of women. Hence, this hayye is an example of a discourse that reinforces existing social realities. The male dominance is created and reproduced by different expressions used in the society with the aim of maintaining status quo. Against this, Furra, former queen of Sidaama, is celebrated as a symbolic figure representing women's freedom.

In the stanzas "Furra the queen of women" and "let the one who killed Furra become small/vanish" the women curse the ones who killed her. The legend tells that Furra was killed by males after being placed on the back of a giraffe. The males killed her as a punishment for oppressing men and for her tricky questions. Metaphorically, Furra is taken as a symbol for women's freedom and the females sing about her longing for their freedom and opposing male oppression. The women narrate this in their hayye hoping to improve their husbands' ill behaviour, which is then the illocutionary force of the stanzas.

There is a certain nostalgia expressed in the stanzas "during the time of Furra husbands even cooked for their wives," like "alas, that she were alive again!" For a culture that maintains a strict division of labour between men and women, this is quite an unexpected and avant-garde attitude, that in these times of female liberation deserves more attention than it normally enjoys.

Thus, the women deny the political realm shaped by men and express symbolically their opposition to being bereft of their freedom in the poetic coinage of this lullaby.

Stanzas from another hayye further illustrate this:

bullichcho daware dawara hogoomma anni'ne amale though I manage to grind the flour, I can't manage your father's behavior marichchinni reekke reekkine worreenna ganinoe seekke?

with what, provided and put here by someone, has he hit me hard?

seekke ganieta ganasi garaho?

when he hit me hard, was his hitting me a right thing to do?

In the above folk medium the women express their dissatisfaction by making allusion from the grinding of corn to the bad behaviour of their husbands. The meaning here illustrates to the hardship of women's life. Usually in rural areas the women grind the corn using the traditional grinder, which is very tiring. 
The above meaning is a symbolic expression where the word "grind" does indicate reshaping or refining of her husband's behaviour. Through the song the women oppose their ill-treatment.

The following are also stanzas from a hayye, that deal with the same topic:

beettu beera gallo

The son stayed at Beera

besere anni gudo beettunnita ganno

Gudo, Besere's father, hit his son's wife

gana garahoni?

Is hitting a right thing to do?

For the interpretation of this hayye it should be noted that there is no formal indicator that shows that the woman sings the lullaby about herself. The word "wife" is not even explicitly mentioned. The only grammatical item that reveals that the song is about an abused woman, is the nominalizing suffix -ta, that together with the case suffix -nni attached to beetto "son" in the form of an oblique case stem (beettu), gives the following information: the object of the mentioned father's hitting activity is a "female entity that is somehow associated with the mentioned son; it could be e.g. his daughter, his mother, or his wife." The performer of the lullaby could sing about herself, or about any other unlucky Sidaama woman, but the general message is: beating a woman is not right.

The whole hayye is a perlocutionary act that is performed through uttering the sentence. Here the singer is asking about the rights of women in the Sidaama society. She is opposing ill treatment of women in general. In Sidaama, hayye, among other genres, is a medium for venting such opposition. Such discourse represents protest media for the women who aspire for their freedom and equality that may be threatened by their male counterparts.

\section{[5.3] Faaro}

The faaro song may belong to different closely related genres, but the transitive derived verb faarsa commonly means "to sing praise". The genre is determined by means of its topic, as the word faaro normally does not occur in its text, in contrast to e.g. the hayye. This dance/song is usually performed by both males and females during festivals and holidays, such as the Fichche (Sidaama New Year). The following is a song of criticism, but implicitly is a praise song. 
A praising faaro

dandoote badachiho sheellu

Shellu from Dandoote son of Badacha (twice repeated)

bixiichcho birra hirteennano

though you have sold bixiichcho (a lump of ensete pulp ready to be fried) for one birr

wondira sok'k'itooti ballo

please, do not let them go to Wondo

wondira ha'rinohu meellu

the women who went to Wondo (twice repeated)

ooso illo soniweelo

gave birth to malformed children

In the above folk media a locutionary act is performed with rhetic acts done by "uttering sentences with sense and more or less definite reference" to the young who might be liable to go to market places in the towns. This faaro is sung in praise of parents who didn't let their children go to towns. In Sidaama, people usually do not go to distant places, particularly cities, believing that it is not a good way of living. Going to towns in previous times was considered as social taboo. Consequently, the young were advised not to go to such places. If they happen to go, they are in the danger of adopting the shameless aspects of urban culture. Metaphorically, this is what is indicated in the syntactic forms above.

The song criticizes those who went to cities and had children there. The stanzas wondira ha'rinohu meellu and ooso illo soniweelo are phatic acts performed by uttering words or sentences in accordance with the syntactic rules. At the same time, the effect of uttering the sentences as perlocutionary acts is urging the members of the society to maintain their norms.

In general, social discourse and communication in a language focus on the cultural and other aspects of the people. This may range from maintaining one's culture to expressing social ills among the people. Austin's locutionary act is discernable as phonetic acts are performed pronouncing the sound "o" as assonance in the three words from the faro above: ooso illo soniweelo "they created malformed children."

This part of the song seems to deal with those women who go to urban areas and have children from illegal unions. Youngsters are advised not to go to towns or cities because there they will learn something that is not culturally acceptable. Through such discourse in the songs the people seek to preserve their culture.

According to the most frequent patterns of Sidaama grammar, the sentence is expected to be [[soniweelo] ooso] illo, the brackets indicating the syntactic 
structure of [[modifier] head]. In other words, part of the song employs the common language structure, whereas other parts follow a less common syntax that might be explained as poetic usage. For the purpose of rhyming and emphasis, the word soniweelo comes in the last part of the construction, so it can rhyme with illo in the following line. In both of these possible word orders soniweelo is tied to the noun ooso as a modifier. This implies that the born child is malformed unless the child is born in marriage. This becomes part of the discourse and demonstrates the extent to which marriage is respected among the people.

The word soniweelo is composed of sona "shape, form, cleanness" + weelo "lacking"; according to the context the composite word may be translated as "ugly, formless, malformed". In this case it is a description of the children who are born as a consequence of the people's culture not being followed. This is a discourse that probably alludes the young who go to towns and cities, where they may be consumed by a new and dangerous culture.

Illo (a two syllable form equivalent to the three syllable word ilino) indicates a happening in the past, being inflected in the past imperfective. It seems to have a masculine subject, indicating the father of the mentioned child, but the subject is meellu, a grammatically masculine word which is an informal equivalent of "women". Here the reference is to women who went away to Wondo.

Austin's locutionary act, particularly the phonetic act, is performed by the acts of pronouncing the sounds " $\mathrm{u}$ " in ha'r-ino-hu and meellu, which were purposefully used with phonological assonance and at the same time it is a perlocutionary act performed with the effect of uttering the clause to warn the young, an illocutionary act. One underlying meaning of the above expression may be to denounce having children outside of marriage. Further, respect of one's tradition, social practices including marriage as an institution are advocated, while the invasion of urban culture from the towns and cities is criticized.

\section{A criticizing faaro}

The following faaro is performed by females criticizing the one who they play faaro with.

kadoohe kandohe

let the one who stepped on you step on you (twice repeated)

midashsho anjohu

one who has smaller ribs

kadoonkehe midashsho anjohu

do not let a resourceless person step on you

hiikkii manchikki handi? 
Where is your bull husband?

handohoni?

Is he a bull now?

handu hadiro hano kando

the bull danced hano in the cattle shed

Usually faaro, which is morphologically and semantically related to "faarsa", refers to praising. Thus, in the faaro players praise each other, or express their love to the one they dance with. In the above lines of the song, however, the male started singing by criticizing the female because her husband didn't control her as she came here to the public place. Indirectly, he wanted to attract the woman. Usually, it is said faaro kadi, which literally means "he danced faro" or "dance faro!" according to the position of high tone. The word kadoohe literally means "let someone step on you". Textually, it seems to be a criticism of the other person, but at discourse level it is the way of alluding to the other party, the woman, by making her ashamed of coming to the dancing place. It is sung like a conversation between the two. The first line is said by the man and the second by the woman as a response to the insult or criticism by the man. While she is dancing with the man she expresses that she is not happy to dance with him at the moment, rather she praised her husband. This song is usually a medium of praising, but it is also a sign to allure the woman into a love affair as in the above instance.

In the following expression the man asked her about the whereabouts of her husband since the man wanted to dance with her: hiikkii manchikki handi? "Where is your bull husband?"

Usually married women dance faaro together with some men. In the song they either appreciate each other or criticize. However, in this expression the man insulted her husband for letting her dance in public space. The next stanza is probably the woman's answer: handohoni? handu hadiro hano kando (=kadino). "Is he a bull now? The bull played hano in the cattle shed!"

Here a locutionary act is performed with the rhetic act of uttering a sentence with more or less definite reference to the husband while talking about the bull. The woman is not interested in the person who dances with her. She expresses her love for her husband by criticizing the man. Culturally, hando is used about a person who is not able to satisfy his wife and who is not able to understand things. As discourse, a bull is usually used as indication of an incapacitated person.

kadoonkehe midashsho anjohu "Do not let the weak (the one with few relatives) step on you." Here the woman is objecting to being abused by her husband. Her husband hits her and she opposes the abuse. She is also criticizing 
him as he does not have many relatives. Midashsho literally denotes "the rib of a person", but it connotes to close and strong (wealthy) relatives. Here the discourse is that if a person does not have close and wealthy relatives, he is not respected even by his wife. Hence, the woman is insulting her husband for such a reason. The illocutionary act is performed by uttering a sentence by the speaker to insult her husband.

A man who suppresses his wife is always criticized in the hayye. In the earlier expression, as the women formerly used to grind crops or cereals using a traditional grinder, they used to express their dissatisfaction on their marriage. Women sing the hayye song as they grind corn and hold babies on their backs.

\section{A faaro love song}

Love songs are made in the form of hano and faaro, which are the common media Sidaama use to pass on the intended message of the singers. Love songs are usually sung in the form of hano by females. Beside that, the faaro is also performed usually by males and females to express their love and appreciation, as in the following:

dansaanni dange dararote

Dange, whose father is Dansa, is a flower

daraarote danise

her face is a flower

danise luubili garro bararise

Her beauty has won the heart.

The phoneme/sound of each line initial word is the same. This is the technique of alliteration and serves for rhythmic purpose. The stylistic features in the poem demonstrate how the people traditionally communicate to express their appreciation using figurative language like "daraarote danise"; this is a sentence where "daraarote" (noun + copula) is the predicative of the clausal subject "danise" (her appearance). Austin's locutionary act comes into work here as both phonetic and phatic acts are performed. First, the word 'daraaro' has a sound effect. It actually refers to the name of a woman and at the same time the beauty of the woman, where it means flower. Thus, the phonetic act here helps to create meaning. The alliteration in the first line, and also in the beginning of each line with the sound "d", is used purposefully for rhythmic value. These are, hence, phonetic acts by pronouncing words in accordance with the phonological rules. In Sidaama, surprisingly, it was observed that the initial sounds of the first and father names are mostly the same, like in Dabasa Dangura, Kebada Kinkino, Batiso Bunkura etc., which give some sort of meaning 
and this has been commonly practiced as the naming tradition of the people.

\section{[6] CONCLUSION}

The Sidaama folk media are quite useful among the people for maintaining the socio-political power and structure within society. At the same time, the folk media has helped to shape the political and social behaviour of members through performing speech acts in the local group. To find out this, both discourse analysis and Austin's speech act principles were applied as a framework.

The folk media reveal an old power structure or relations between the dominant 'melkanna' and the subordinated (the local people) as manifested in the discourses. The folk forms as discourse media are used to denounce past oppression and to ventilate present grievances. Through the folk media the people also object to the new cultural intrusion and domination. Though the texts seem to indicate some superfluous meanings, they have, in reality, deeper meanings.

In order to better analyse the discourses, Austin's speech act theory was used. This is because the analysis of Austin's speech acts helps in making the discourses more discernably about the political and social matters as portrayed in the folk media. The people use various folk media to perform different acts that enable the people to perform some acts with reference to societal values and good deeds of individuals. They carry out acts with the intention of creating some effect, a perlocutionary act, like performing hayye to send a baby to sleep, and perform an act while it also implicitly forces the hearer to perform an act based on the desires of the utterer. In hano, the same happens, but where the speaker utters a speech such as that in the hano he or she performs the speech act, locutionary act with rhetic acts done by uttering words or sentences with sense and more or less definite reference. At the same time, the acts indicate some deeper level meanings as discourse forms. The folk media such as hano, faaro and hayye are very common among the people to sustain the power and politics among the people, which indicate the dominant and subordinate relations. The folk media, with the songs and the rituals and others, help in linguistic and cultural negotiation towards performing acts that are commonly agreed upon by the people. These folk media are the manifestations of the social and political discourses, communication and the cultural practices among the people.

Basically, folk media are used in different speech contexts for making some discourses. They are the means which social meanings are created and communicated, and discourses are made. In other words, folk forms are the media through which the Sidaama people pass on messages for informing, educating, 
persuading and entertaining generations, as do the modern mass media. The Sidaama folk media such as faaro, hano, and hayye are used to mediate the political and social discourses of the people. The political and social discourses in the folk media demonstrate that lexical and semantic uses are exploited to the utmost to create meanings for various contexts. Thus, the people use hano, faaro, and hayye as folk media for social and political ends.

\section{REFERENCES}

Anbessa Teferra. 2007. The structure of Sidaama nouns. From beyond the Mediterranean. Akten des 7 internationalen Semitohamitistenkongresses, Berlin 2004. Ed. Rainer Voigt. Berlin: Shaker. 185-195.

Anbessa Teferra. 1987. Complement Clauses in Sidamo. Unpublished M.A Thesis, Addis Ababa University.

Austin, John L. 1962. How to do Things With Words. Oxford: The Clarendon Press.

Bahru Zewde and Siegfried Pausewang (eds.). 2002. Ethiopia: The Challenge of Democracy from Below. Uppsala and Addis Ababa: Nordiska Afrikainstitutet.

Betana Hotesso. 1991. Sidaama: Hezbina Bahlu (Sidaama: People and Culture). Addis Ababa: Bole Printing Press.

Carey, J. W. 1989. Communication as culture: Essays on media and society. Winchester, MA: Unwin Hyman.

Central Statistical Agency. 2007. Population Census. Addis Ababa.

Craig, Robert T. 2008. Pragmatism in the Field of Communication Theory. Paper presented to the Annual Conference of the International Communication Association, Dresden, Germany.

Essien, Coleman F. 2014. Indigenous Media and Rural Development: The Case of Oil Producing Communities in Akwa Ibom State, Nigeria, Online Journal of Communication and Media Technologies Volume: 4 - Issue: 2.

Gee, James Paul. 2011. An Introduction to Discourse Analysis: Theory and method. Third Edition: New York: Routledge.

Girum Tesfaye .2013. Ideophones in Sidaama: Documentation and Description. Addis Ababa: Unpublished M.A Thesis, Addis Ababa University 
Hamer, John. 1970. Sidamo Generational Class Cycles: A Political Gerontocracy. Africa 15(1): 50-70.

Henze, Paul. 2001. Layers of Time: The History of Ethiopia. London: C. Hurst and Co.

Hudson, G. 2006. Highland East Cushitic Languages. MI, USA, Elsviere Ltd.

Kumar, Harish .2006. Folk Media and Rural Development, Indian Media Studies Journal. Vol.1:1.

Markos Tekle. 2014. State-Society Relations and Traditional Modes of Governance in Ethiopia: A Case Study of Sidaama. Addis Ababa: Addis Ababa University (Unpublished).

Markos Tekle, Zinash Tsegaye, Desalegn Garsamo, Geremu Garje and Beyene Bada. 2011. Sidama History and Culture. Hawassa: Sidama Zone Culture, Tourism and Government Communication Affairs Department.

Mayr, Andrea. 2008. Language and Power. An Introduction to Institutional Discourse. London Continuum International Publishing Group.

Mclnelly, Brett C. and Dennis R. Perry. 2007. Writing and Rhetoric. Michigan: Hayden-McNeil Publishing.

Mesay Bogale. 2016. Cultural Communication in Sidaama. Addis Ababa: Unpublished M.A Thesis, Addis Ababa University

Moeschler, Jacques (u.d). Speech Act Theory and the Analysis of Conversations. Sequencing and interpretation in pragmatic theory. University of Geneva.

Mundy, Paul. 1993. Indigenous Knowledge and Communication: Current Approaches, Development, The Journal of the Society for International Development.

Morand, David A. 2000. "Language and power: an empirical analysisof linguistic strategies used in superior/subordinate communication". Journal of Organizational Behavior 21, 235-248.

Murdock, George, Peter. 1959. Africa: Its Peoples and Their Cultural History. New York: McGraw Hill.

Nigussie Meshesha. 2005. Culture and Gender in Sidama Folk Poetry. Addis Ababa: Addis Ababa University (Unpublished).

Nigussie Meshesha. 2015. Folk Communication and Governance System in 
Sidaama and Gedeo Peoples. Proceeding of 2nd National Conference: Mettu: Mettu University.

Nimmo, D. D. and Sanders, K. R. (eds.). 1981. Handbook of Political Communication. The Use and Abuse of Language Evidence in Language crimes. Beverly Hills, CA: Sage.

Oishi, Etsuko. 2006. Austin's Speech Act Theory and the Speech Situation. Esercizi Filosofici 1, pp. 1-14 Retrieved from http://www.univ.trieste.it/ eserfilo/art106/oishi106.pdf

Riemer, Nick. 2010. Introducing Semantics. New York: Cambridge University Press.

Sidaama in Ethiopia. Retrieved on July 7, 2015. Retrieved from http://joshuaproject.net/people_groups/14630/ET.

Syal, Pushpinder and D. V. Jindal. 2002. Introduction to Linguistics. New Delhi: Prentice Hall of India.

Tagliamonte, Sali A. 2006. Analysing Sociolinguistic Variation. Cambridge: Cambridge University Press.

Tafesse Gebremariam. 2015. Personal Names in Sidaama. Addis Ababa: Unpublished M.A Thesis, Addis Ababa University.

Van Dijk, T. A. 1993. "Principles of experience into social science critical discourse analysis." Discourse and Society 4(2), 249-83.

Yri, Kjell Magne. 2004. Orthography and phonology in Sidaamu Afoo (Sidamo). JES, Vol XXXVII:1.

Yri, Kjell Magne. 2011. The Phonology of "Sidaamu Afii Jirte": implications for the orthography of Sidaama. JES, Vol XLIV.

\section{AC KNOWLEDGMENTS}

We would like to extend our sincere gratituiude to the NORHED/NORAD Lingustic Capacity Building Project - Tools for the Inclusive Development of Ethiopia as it has provided us with the necessary financial support for conducting the study. This paper also has benefited from the constructive and insightful comments of Girum Tesfaye, Hawassa University. Further, Yaicob Wayu and Shimelis Gizaw have contributed with their knowledge about the interpretation and performance of some of the selected songs/dances. 
CONTACTS

Nigussie Meshesha Mitike

School of Languages and Communication Studies, Hawassa University

nigussiemeshesham@gmail.com

Kjell Magne Yri

Department of Linguistics and Scandinavian Studies

University of Oslo

kjellmy@iln.uio.no 
